\title{
Anesthesia and the role of short-term service delivery in developing countries
}

\author{
[L'anesthésie et le rôle des offres de services à court terme dans les pays en \\ voie de développement]
}

Alison Froese MD FRCPC

Purpose: To clarify the ongoing need for involvement of anesthesiologists in short-term surgical projects in developing countries, and provide information to guide the selection of, application for, and preparation for these rewarding experiences.

Observations: The lack of safe anesthesia services severely limits the performance of needed surgical procedures in developing countries around the world. Even in countries where well-trained anesthesiologists are available in major urban centres, resources are often absent or limited for large numbers of people in rural or remote areas. Anesthesiologists are highly sought members of surgical teams. Internet sites provide extensive project information. Projects occur in Central and South America, Africa, Asia and Eastern Europe. Projects can bring specialized surgical expertise to an otherwise well-serviced urban area, or work in remote areas that have surgical services only when a team comes. Available equipment, drugs, housing, food and transportation vary markedly with project site. Flexibility, adaptability and problem-solving skills are essential. Translators provide language assistance. Anesthesiologists who have experience providing anesthetics in settings with less technological support can assist other anesthesiologists in adapting to less sophisticated settings.

Conclusions: Severe shortages of trained health professionals plague developing countries, reflecting complex economic and political problems that will require decades for resolution. Until such time as surgical services are widely available and affordable in remote as well as urban areas of developing countries, anesthesiologists will continue to provide a valuable and personally rewarding contribution through short-term assistance.

CAN J ANESTH $2007 / 54: 11 /$ pp 940-946
Objectif : Clarifier le besoin suivi de l'engagement des anesthésiologistes dans les projets chirurgicaux à court terme dans les pays en voie de développement, et fournir des renseignements afin de guider la sélection, la candidature et la préparation de ces expériences enrichissantes.

Observations: Le manque de services d'anesthésie sécuritaires limite sérieusement la performance de procédures chirurgicales nécessaires dans les pays en voie de développement du monde entier. Même dans les pays où des anesthésiologistes bien formés sont disponibles dans les centres urbains les plus importants, les ressources font souvent défaut ou sont limitées pour une grande partie de la population résidant dans des zones rurales ou reculées. Les anesthésiologistes sont des membres très prisés des équipes chirurgicales. Des sites Internet fournissent des informations détaillées sur les projets. Les projets ont lieu en Amérique Centrale, en Amérique du Sud, en Afrique, en Asie et en Europe de l'Est. Ces projets permettent d'offrir une expertise chirurgicale spécialisée dans une zone urbaine bien desservie, ou de travailler dans des zones reculées qui n'ont de services chirurgicaux que lorsqu'une équipe s'y rend. La mise à disposition d'équipements, de médicaments, de logement, de nourriture et de transport varient de façon importante selon les projets. Afin de garantir leur disponibilité, il est possible d'apporter des médicaments et des équipements suggérés. La flexibilité, l'adaptabilité et une habileté à résoudre des problèmes sont essentiels. Des traducteurs fournissent une assistance linguistique. Des anesthésiologistes habitués à pratiquer l'anesthésie dans des contextes où le soutien technologique est moins important peuvent assister d'autres anesthésiologistes dans leur adaptation à ces environnements moins sophistiqués.

Conclusions : D’importantes pénuries en personnel médical formé sont un fléau dans les pays en voie de développement, reflétant des problèmes économiques et politiques importants qui nécessiteront des décennies avant d'être résolus. En attendant que des services chirurgicaux soient aisément disponibles et abordables dans les zones reculées aussi bien qu'urbaines des pays en voie de

From the Departments of Anesthesiology, Physiology and Paediatrics, Kingston General Hospital, Queen's University, Kingston, Ontario, Canada.

Address correspondence to: Dr. Alison Froese, Department of Anesthesiology, Kingston General Hospital, 76 Stuart St., Kingston, Ontario K7L 2V7, Canada. Phone: 613-548-7827; Fax: 613-548-1375; E-mail: froesea@kgh.kari.net

Competing interests: None declared. The author has no commercial connections or consultancies. Accepted for publication August 23, 2007.

Revision accepted September 10, 2007. 
développement, les anesthésiologistes continueront de fournir une contribution précieuse et gratifiante par le biais de l'assistance à court terme.

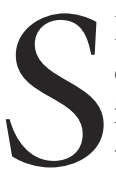
HORTAGES of trained health professionals, drugs and equipment make surgical services inaccessible for millions in developing countries worldwide. For many, poverty limits access to the limited resources that are available. Significant contributions to health care are made when teams of volunteer professionals staff short-term (one to two weeks) surgical projects in such settings, providing the needed skills, drugs and equipment, with little direct cost to the patients. Numerous humanitarian groups organize such projects, with anesthesiologists being highly-sought members of such teams. . $^{\mathrm{A} B}$

The development of anesthesia training programs in developing countries remains a fundamentally important initiative. It follows the old adage "teach a person to fish, and they eat for a lifetime". The Canadian Anesthesiologists' Society International Education Fund (CASIEF) has made significant contributions of this nature over the past 20 plus years. ${ }^{1}$ Such advances have not, however, made short-term projects obsolete. The "fishing rods" are still inadequate in number and unevenly distributed.

Not surprisingly, the distribution of health care is as problematic in developing countries as it is here in Canada. Access to Cesarean delivery or other surgical procedures is as unavailable in many communities in northern Canada as it is in rural Nepal or numerous other developing countries. The degree of "underservicing" is simply more extreme in developing countries. Our underserviced northern regions at least have a medical evacuation option if someone makes the diagnosis and the planes can fly. Such is not the case for millions elsewhere.

Unfortunately, the establishment of anesthesia training programs is no more likely to rectify the maldistribution of health care professionals in developing countries than the many failed strategies trialed in Canada and other developed nations. Starting in the 1980s, the CASIEF established a training program in Kathmandu, the capital city of Nepal. ${ }^{1}$ Not surprisingly, to date many of the anesthesiologists trained through this program practice in urban areas. Studies in developing countries reveal that trained health care workers gravitate to major cities and training centres, just as in Canada. ${ }^{\mathrm{C}, 2-4}$ The greater the training, the greater the likelihood a physician or nurse will work in a major city or emigrate. Faced with the pervasiveness of this reality, the need for short-term projects remains.

In a recent survey of anesthesia providers attending a training event in Uganda, when 91 respondents were asked to make free-text comments about ways in which anesthesia could be improved in their hospitals, 86 identified availability of anesthetic equipment as their number one limiting factor. ${ }^{5}$ Availability of drugs was identified by 46 . The need for more anesthesiologists was mentioned by only 28 respondents and a need for better supervision by 11 . In essence, individuals with some level of training were too often unable to utilize what skills they had because of lack of equipment, basic drugs, reliable oxygen and electricity, intravenous fluids and other such fundamental infrastructure. In such a setting additional trained personnel can only be of help if they bring the necessary resources with them. That - in essence - is the nature of a short-term surgical project in a developing country. The short-term project is a stopgap measure, but one that addresses immediate needs while longer term solutions are sought.

Anesthesiologists are a highly sought resource by groups organizing such projects. During a debriefing session at the end of one project in the Philippines, a young Filipino surgeon who ordinarily worked in a rural hospital with rare anesthesia coverage was asked for his reflections on the project. For him, the most memorable feature was the experience of actually having patients under general anesthesia for excision of very large goitres and only having to focus on the surgery. Being able then to give his full attention to the surgical instruction he received from a visiting expert endocrinological surgeon was viewed as a secondary benefit. Unfortunately, some projects occur without anesthesia coverage because of lack of volunteers.

A IMVA.org [homepage on the Internet]. Woodville, MA: International Medical Volunteers Association; formed 1996 (updated Jan 6, 2006). Available from URL; http://www. imva.org/Pages/orgdb/wblstfrm.htm (accessed September 10, 2007).

B International Health Volunteers.org (database on the Internet). Academy of Medicine; Duval County Medical Society.;c2002 (updated 2007 with June project information). Available from URL; http://www.internationalhealthvolunteers.org (accessed September 10, 2007).

C Health workers: a global profile: World Health Organization Report, 2006. Especially figure 1.3. Available from URL; http://www.who.int/whr/2006/06_chapl_en.pdf (accessed September 10, 2007). 


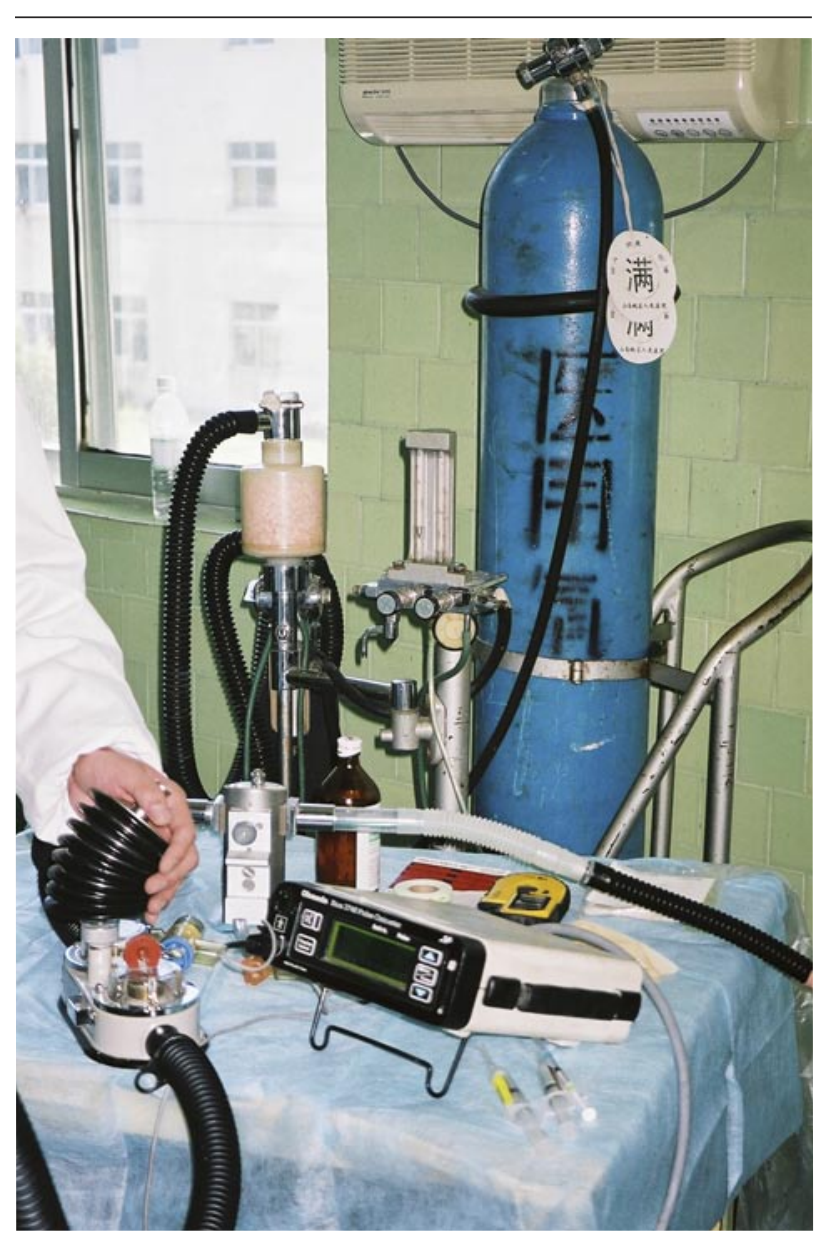

FIGURE 1 Anesthesia 'system' assembled in Tibet using the oxygen tank and flowmeter (the only functional components) from a retired anesthesia machine found under a sheet in a corner combined with a draw-over halothane vaporizer and Oxford hand-operated ventilating bellows brought from Nepal. The availability of two $\mathrm{SaO}_{2}$ monitors was reassuring when working at an altitude of $3500 \mathrm{~m}$.

\section{Types of projects}

Many humanitarian groups organize surgical projects. ${ }^{6}$ Some of these groups are North American-based; some operate from within the receiving country but have administrative connections with some North American organization. The International Medical Volunteers Association (IMVA) website outlines who pays for transportation to the site, housing, and food. ${ }^{\mathrm{A}}$ A few organizations cover all or most of the costs. The majority of the organizations are solely donor-funded and the volunteer covers costs, with charitable receipts provided for such expenses. Organizations usually assist with travel arrangements. Some (for example Medical Ministry International, www.mmint.org) arrange group travel and medical insurance for participants, including medical evacuation should it be needed. Websites of the individual organizations provide detailed information plus contact people to address specific questions. $\mathrm{A}, \mathrm{B}$ Regulatory requirements vary. In some cases proof of active licensure and hospital privileges in Canada, plus a brief curriculum vitae are all that is required. However, one senior academic surgeon (personal communication) applying to Swaziland had to supply extensive documentation back to and including high school records. When his license eventually arrived it bore the number ' 1 '. The comments below are limited to my experience of 12 trips over the past six years in three countries, the Philippines (mainly in Mindanao), Nepal and Tibet.

Groups vary in their makeup. Some use the 'parachute' approach. In this scenario, a group of North Americans, (or Europeans, Australians or New Zealanders) assembles personnel and equipment and descends on a community, having little integration with local personnel, to address a particular target populations with problems such as cleft lips \pm palates, ocular diseases, or gynecological disorders. Generally one is given access to an operating room (OR), a sterilizer, and a few local personnel (including translators who may have no familiarity with medical issues). Local physicians may or may not choose to use the project as a training opportunity. Often a non-governmental organization sees a need and initiates the invitation for such a project and makes local arrangements for travel, housing and some hospital venue in which to work, but may have no one actually positioned within the hospital. Such settings require a high degree of selfsufficiency and resourcefulness in the team. Personal experience with this approach working in the Regional Hospital of a city in Tibet suggests that this is not the setting for a first-time volunteer (Figure 1).

A second approach combines out-of-country and in-country volunteers to work together for a one-or two-week period in an underserviced setting. This approach provides strong integration with the host country. I have experienced this in the Philippines and Nepal. There are many advantages to this approach. The out-of-country volunteers contribute their skills, supplies, specialized equipment and some financial support for the project. (In the Philippines, some of the 'project fees' are used to buy rice to feed patients and families camped on the hospital grounds while either awaiting for or recovering from surgery). The in-country volunteers contribute their skills, their knowledge of language, needs, resources, creative solutions and cultural expectations. Integration of the project with local personnel provides the neces- 
sary postoperative care and follow-up after the team departs, broadening the range of surgical procedures one can attempt safely. The involvement of in-country professionals also provides the out-of-country volunteer a chance to ask local colleagues how they handle particular procedures with the resources at hand. Once the suggested approach has been tried one's own modifications can be added.

\section{Project settings}

Project settings vary and flexibility is an essential prerequisite. Last-minute changes in venue can be triggered by anything from political unrest to severe acute respiratory syndrome. I work on the basis that if the in-country team members view that it is safe to carry out a project in a given site, I will go. Access to health care varies within cities in developing countries, not just between urban and rural areas. Therefore some projects occur within urban settings that have year-round surgery and anesthesia services, but which cannot provide certain types of surgical procedures (e.g., some plastic procedures or complex otorhinolaryngology), or cannot afford to treat everyone for free, and therefore schedule indigent patients needing elective surgery for when the team comes. These settings are the most comfortable for a novice volunteer. One is likely to encounter an anesthesia machine with one or more Tec 2-4 era vaporizers, at least an oxygen saturation monitor and a $\mathrm{CO}_{2}$ absorber. A working ventilator is unlikely, but sterile gowns, drapes, disposable needles, basic drugs, a staffed recovery room, and a preoperative history and physical will probably be available. Two OR tables in the same room is standard procedure during a team's visit. This is a good setup for a senior anesthesia resident participating in these projects to learn to use clinical observation to compensate for less technology, since the supervising anesthesiologist can administer an anesthetic and supervise concurrently (Figure 2).

Intermediate settings have an established clinic or small hospital but surgery is available only when a volunteer team arrives. Here one is still likely to have some type of anesthesia machine with a circle system, at least a halothane vaporizer, tank $\mathrm{O}_{2}$, the drugs and endotracheal tubes which you bring, and the oxygen saturation monitor which you have supplied. A more sophisticated monitor may be available and operational. In this setting 'sophistication' means having electrocardiogram, $\mathrm{SaO}_{2}$, and non-invasive blood pressure monitoring capabilities. Recovery room staff may be available. If so, they will be dedicated but have limited training. Access to narcotics will likely be very limited (agents such as nalbuphine and intravenous

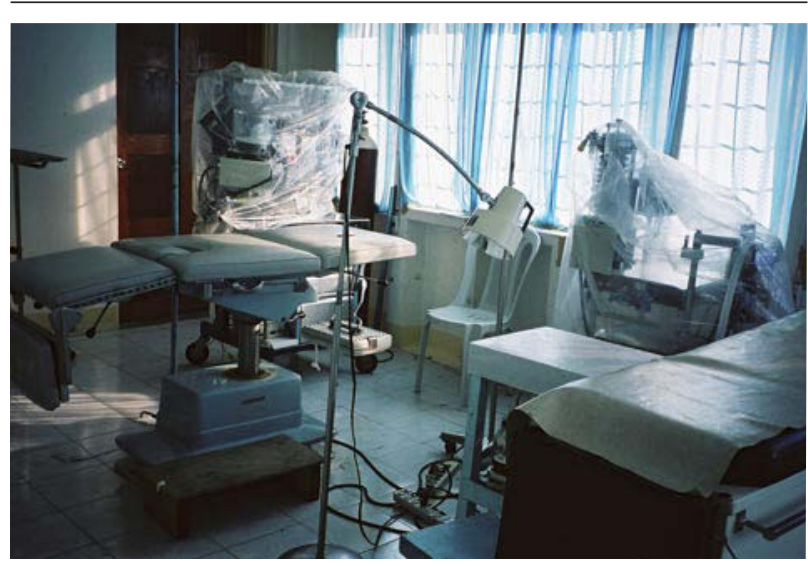

FIGURE 2 This equipment in an operating room in southern Mindanao in the Philippines is only used when a volunteer team arrives once a year. The oxygen flowmeters, carbon dioxide absorbers and one or two vaporizers per machine are the only remaining working components of the anesthesia systems donated several years ago. Additional items needed for anesthesia and surgery are brought from a larger hospital in northern Mindanao and by the North American team members. With a two-table setup help is always close at hand.

tramadone are often the only ones available). It is remarkable to observe how stoical patients are in these settings and how little nausea and vomiting occurs postoperatively in the absence of narcotics.

Certain less developed settings which have previously provided limited surgical services may have an unused OR in the local hospital, or can convert a delivery room or a procedure room into an OR (or "theatre") for the duration of the project. I have experienced this arrangement in three remote sites in Nepal. Two of these sites could be accessed only by using a chartered plane (team participants did not have to cover those costs)! One was accessible by a 12hr trip in Land Rovers, much of it via hairpin-turns on mountain roads through incredible scenery. Anyone with a tendency to motion sickness was given prophylactic antinauseants and priority access to a front seat.

In these settings the team brings everything that will be needed. This includes portable items such as a draw-over anesthesia vaporizer, hand-operated ventilating bellows, non-rebreathing valves (the latter two items in both adult and pediatric sizes) laryngoscopes, endotracheal tubes, drugs, oxygen concentrator, generator, sterilizers, blood pressure cuffs, saturation monitors, spinal needles, intravenous cannulae and intravenous solutions, possibly some type of starch polymer volume expander, surgical instruments and electrosurgical units. The majority of these items are 
provided by the Nepalese organizers. Under these circumstances patients essentially need to be recovered on the OR table until supplemental oxygen is no longer needed. Anesthesiologists (in my experience) are encouraged to establish criteria for the type and age of patient they are comfortable managing with these resources. For example, one may decide to anesthetize patients with a cleft lip who are as young as four or five months of age, but not to anesthetize a child where there is potential for significant procedure-related blood loss (as with a cleft palate repair) until the patient's weight exceeds $10 \mathrm{~kg}$. In one rural setting in Nepal this requirement limited palate repairs to children four or five years and older. A preoperative history is rare although a hemoglobin level is usually available. The physical assessment occurs as the patient enters the OR. In many mountainous settings the individual's survival under rigorous conditions (including high altitude) guarantees that they have an adequate exercise tolerance. In my times in Nepal I have been impressed with the range of problems that can be managed safely and successfully on such 'camps' in remote areas of the country.

\section{The challenges}

Despite planning and appropriate preparation problems do occur. The anesthesiologist may be called from his/her general anesthetic case to deal with airway obstruction in a patient having surgery under local anesthesia. (Was this too much lidocaine on both recurrent laryngeal nerves? Is this tracheal collapse from tracheomalacia following excision of a long-standing goitre?) However, someone will always squeeze the bag for the patient one leaves behind while multitasking for a while. The only functioning monitors may end up being the extra $\mathrm{O}_{2}$ saturation monitor you brought, and one's finger on the pulse. Nevertheless, that is sufficient to provide for safe anesthesia with many procedures in these settings. One should not be surprised when asked if your anesthetized patient can manage without the $\mathrm{O}_{2}$ concentrator so the electricity supply can be used to take $x$-rays elsewhere in the hospital. One may also be surprised to find the supplemental oxygen wasn't, in fact, needed for that particular patient. When necessary, one can always say 'No'. Some patients will bleed excessively in the absence of a blood bank. 'Volunteering' sometimes includes impromptu blood donation when not enough family members crossmatch successfully. However, the benefit is warm whole blood full of clotting factors for your patient. Alternatively, blood from the abdominal cavity filtered through a gauze and reinfused still substitutes for a proper cell saver in an emergency.
For some anesthesiologists providing short-term services in these settings, food and housing can be challenging. Accommodation is generally the best available at a given site, but the best can range from comfortable dormitory-type accommodations to a 'hotel' with mud floors, an outdoor privy with Asianstyle toilet, and no shower facilities. Prior camping experience can be useful. Food will also be the best available at any give site, but this can range from a table covered with platters of delicious options, to a breakfast consisting of a fried egg on a fried roll and hot water. Flexibility helps. When all else fails there is usually plenty of rice (or some local carbohydrate equivalent). One general rule: the more primitive the accommodations, the more incredible the scenery.

\section{The rewards}

Anesthesia is an excellent specialty for short-term projects. (How does one make a long-term impact on diabetes or hypertension in two weeks?) On a surgical project one sees immediate results. Once a fibroidfilled uterus of 32 weeks gestation size is removed, it's gone for good and so is the chronic anemia resulting from it. Once a cleft lip is repaired that child will be allowed to go to school in Tibet. Once a cleft palate is repaired, intelligible speech becomes possible. Once a burn contracture is released - one that may have restricted movement for two, ten, or 15 years - an arm, fingers or leg is freed for use again. Once a uterus that has been prolapsed for 25 years is excised a woman will sit, walk and work comfortably again. It is rewarding to see someone who has had a huge goitre for years exploring what it is like to be able to turn one's head again, and swallow, or sing. Once a teen with congenital club feet or tight Achilles tendons has surgery and physiotherapy, his/her life will be transformed. Impromptu donations totalling $\$ 50$ from local nurses just prior to my departure for Nepal one year funded the total care for bilateral Achilles tendon releases, transportation by bus to a charitable Pokhara hospital after being carried for eight hours through the mountains to the beginning of the road, repeated casting, and physiotherapy for a 13-yr-old girl who hadn't walked since the age of three.

Short-term service delivery in developing countries provides opportunities to encourage and train local heath professionals, while also learning from them. It is humbling to experience the gratitude of patients whose disease could not be cured, but who are grateful you cared enough to try. One has no doubt about whether the project is appreciated when you learn the local school teacher has used her month's vacation over Christmas to feed coconut shells under the iron 
pot sterilizer so that gowns, sponges and drapes can be ready for the team's arrival.

There are also learning points one might never otherwise encounter. Where else would one learn how many times a 'disposable OR gown' from Canada can be washed and resterilized before it disintegrates? Where else could one practice how to estimate blood loss when the lap sponges are routinely wrung out into a pail and then re-used because otherwise supplies would run out before the patients did? Where else could you find yourself on 'reality TV' as curious onlookers crowd around the OR windows peering through the thin curtains at a late night operation?

\section{Essential equipment}

We anesthesiologists all have our preferred ways of doing things. It is worthwhile to analyze what items make one function more comfortably and to determine if they can fit into your suitcase. My essentials include two laryngoscope handles, and my preferred adult and pediatric blades; a battery-powered oxygen saturation monitor, a gum elastic bougie, a rigid light wand, \#4, 3, 21/2, 2, 1 1/2 laryngeal mask airways, several $100 \mathrm{~mL}$ intravenous bags and phenylephrine, large bore intravenous cannulae, and the items I like to use for paravertebral blocks, which may be the only real analgesia I can offer after a thoracotomy or nephrectomy. I also take a supply of endotracheal tubes, some adult and pediatric reservoir bags and a selection of drugs that I want available whether they are part of the local 'drug box' or not. My list includes labetalol, esmolol, glycopyrrolate, neostigmine, dexamethasone, an ampoule of calcium chloride, a few ipratropium bromide and salbutamal nebules to treat bronchospasm, and ketoralac. I depend on local supplies of atropine, since it is considered a 'dangerous drug' in some countries. Many of the above items fit into a small tool box that can easily move from place to place. I consider halothane an essential resource for mask induction of a potentially difficult airway, such as with burn contractures of the neck. Anything electrical that I take is prominently marked ' 110 volts' on the device and its plug, in an attempt to prevent disaster from its connection to a 220 volt power source.

The World Federation of Societies of Anaesthesiologists has produced guidelines outlining the bare minimum of resources - drugs, equipment and infrastructure such as clean water - needed for the safe administration of anesthetics for adults, children and Cesarean deliveries in developing countries. Revised versions are provided in the paper by Hodges et $a .^{5}$ None of these lists includes sevoflurane or desflurane. Isoflurane is considered to be a luxury drug' (costing three times as much as halothane in the Philippines) in all sites where I have worked. We can only hope that our current lack of access to halothane in Canada does not spread worldwide.

The degree of assistance available to the anesthesiologist varies from site to site. In the Philippines, when dealing with a potentially difficult airway, I have always had the help of another anesthesiologist or a very experienced Filipino nurse (who also becomes my unofficial 'nurse anesthetist' when a spinal runs out on the second OR table before the surgery is completed). In one remote area of Nepal we had equipment for one general anesthetic and one conscious sedation or ketamine case, but two anesthesiologists. That meant that we could always assist each other for the induction and emergence of babies and small children. At the other extreme, I learned quickly in Tibet to doublecheck that I had some English-speaking nurse or surgeon with an appropriate skill set available in the room before starting an inhalation induction on a child. That person would be needed to hold the airway while I started an intravenous, or respond to my requests for specific items that were unfamiliar to the non-medical translator who was there to facilitate communication with the patient and the Tibetan nurses.

Every team varies in its makeup and skills. It often takes a day or two to determine the optimal use of personnel. The first day is always challenging and I always insist that my first case in a new site is either an adolescent or an adult. The infants can be scheduled for another day once the availability of all needed resources has been verified and it is certain that all tasks are appropriately covered. For example, at one site I learned that the 'recovery room' had not yet been identified and staffed when I was led to the outpatient department with my first groggy patient. Then, when directed to a stretcher in the emergency room, I soon realized that all the people eagerly surrounding me were family members. Not a nurse could be seen. Our New Orleans emergency room nurse, a veteran of Hurricane Katrina, was soon assigned recovery room duty with no further problems.

In some locations, all patients - including babies - arrive with an intravenous cannula in situ. This is extremely useful for patients baking in the tropical heat while awaiting their turn in the OR. It also enables one to administer a 'snooze dose' of propofol or thiopental to children at the doorway before entering the OR so that they will not be confronted by the sight of the patient undergoing surgery on the second table in that OR. However in another site I quickly learned it was wiser to start my own intravenous since the routine (and only) ward intravenous was a $25 \mathrm{G}$ butterfly. 


\section{Long-term solutions}

Many of the factors limiting the provision of health care in developing countries require major political and economic advances before self-sufficiency will be attained. Shortages of equipment and drugs frequently limit professionals from being able to use the training they already have. ${ }^{1,5}$ Conflict in some countries destroys the clinics, hospitals and health centres that those regions cannot afford to replace. The emigration of trained professionals is driven by both unemployment or dismal wages at home and vigorous recruitment by developed countries struggling with work force shortages. ${ }^{3,7,8}$ United States shortages, predicted to be 200,000 physicians and 800,000 nurses by 2020 , dominate the international flow of health professionals. ${ }^{7,9,10}$ It is widely agreed that current shortages in the United States, Canada and United Kingdom have resulted from setting inappropriate targets for training positions in the 1990's. ${ }^{3,9,11}$ It will take years, however, to rectify the consequences of these decisions. Until then, developing countries will continue to bleed trained professionals into the global work force market. Over $60 \%$ of the International Medical Graduates in the United States come from lower-income countries; this percentage is $43 \%$ for Canada. ${ }^{12}$ Six of the countries with the highest emigration ratio are in subSaharan Africa. Three are in the Caribbean region. ${ }^{12}$ While the Region of the Americas contains only 10\% of the global burden of disease, it has almost $37 \%$ of the world's health workers and spends more than $50 \%$ of the total globe's health-related resources. Africa has more than $24 \%$ of the disease burden, $3 \%$ of the globe's health workers, and less than $1 \%$ of global financial health resources even when loans and grants are taken

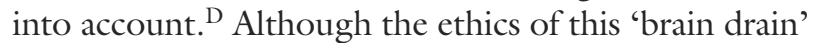
has been deplored by many, ${ }^{3,8,9,11}$ voluntary restraining measures have proved ineffective. ${ }^{11}$

It has been suggested that receiving countries should at least be required to reimburse donor countries for the education cost of the professionals they receive, ${ }^{8,13}$ but I am unaware that this ever occurs. Until such time as developed countries are training and retaining an adequate number of health professionals, the current drain from developing countries will persist. ${ }^{3,7,9}$ In the interim, short-term projects represent a temporizing way to repay some of our debt to developing countries for the training they have invested in approximately $25 \%$ of our Canadian physician workforce. ${ }^{9}$

\footnotetext{
D Health workers: a global profile: World Health Organization Report, 2006. Especially figure 1.2. Available from URL; http://www.who.int/whr/2006/06_chapl_en.pdf (accessed September 10, 2007).
}

In conclusion, severe shortages of trained health professionals plague developing countries, reflecting complex economic and political problems that will require decades for resolution. Until such time as surgical services are widely available and affordable in remote as well as urban areas of developing countries, anesthesiologists will continue to provide a valuable and personally-rewarding contribution through short-term assistance.

\section{References}

1 Tweed WA, Amatya R, Tuladhar TM, Maltby JR, Gurung CK, McCaughey TJ. Anaesthesia services and the education of anaesthetists in Nepal: a model for sustainable development? Can J Anaesth 1993; 40: 993-9.

2 Barden-O'Fallon J, Angeles G, Tsui A. Imbalances in the health labour force: an assessment using data from three national health facility surveys. Health Policy Plan 2006; 21: 80-90.

3 Kingma $M$. Migration patterns of health professionals (French). Cah Sociol Demogr Med 2005; 45: 287306.

4 Marchal B, Kegels G. Health workforce imbalances in times of globalization: brain drain or professional mobility? Int J Health Plann Manage 2003; 18(Suppl): S89-101.

5 Hodges SC, Mijumbi C, Okello M, McCormick BA, Walker IA, Wilson IH. Anaesthesia services in developing countries: defining the problems. Anaesthesia 2007; 62: 4-11.

6 Vastag B. Volunteers see the world and help its people. JAMA 2002; 288: 559-65.

7 Brush BL, Sochalski J. International nurse migration: lessons from the Philippines. Policy Polit Nurs Pract 2007; 8: 37-46.

8 McElmurry BJ, Solheim K, Kishi R, Coffia MA, Woith $W$, Janepanish $P$. Ethical concerns in nurse migration. J Prof Nurs 2006; 22: 226-35.

9 Chen LC, Boufford JI. Fatal flows--doctors on the move (Editorial). N Engl J Med 2005; 353: 1850-2.

10 Aiken LH. US nurse labor market dynamics are key to global nurse sufficiency. Health Serv Res 2007; 42(3:Pt 2): 1299-320.

11 Watkins $S$. Migration of healthcare professionals: practical and ethical considerations. Clin Med 2005; 5: 240-3.

12 Mullan $F$. The metrics of the physician brain drain. N Engl J Med 2005; 353: 1810-8.

13 Buchan J, Sochalski J. The migration of nurses: trends and policies. Bull World Health Organ 2004; 82: 58794. 